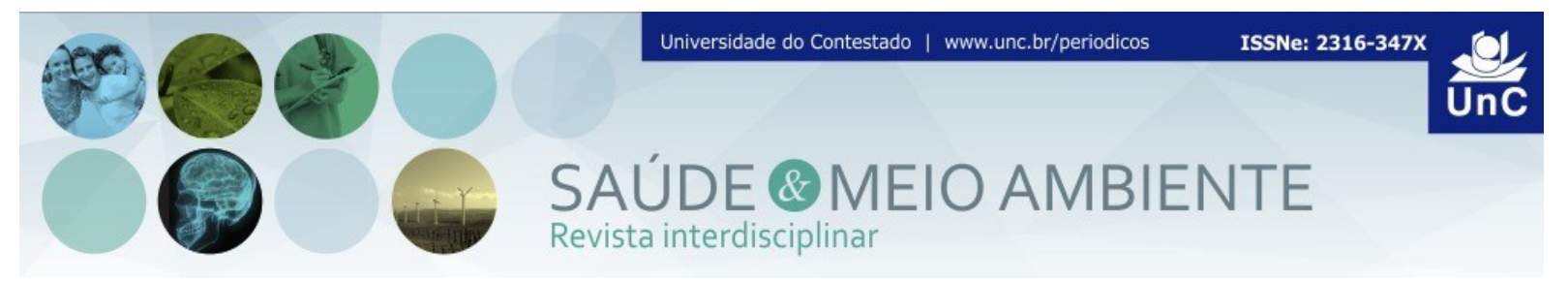

\title{
ANÁLISE DA TRANSPORTABILIDADE DE RESTOS ESQUELETAIS DO BONE BED DE PTEROSSAUROS DE CRUZEIRO DO OESTE, GRUPO CAIUÁ, CRETÁCEO DA BACIA SEDIMENTAR DO PARANÁ ${ }^{1}$
}

Morgana Denk Wantowsky² Luiz Carlos Weinschütz ${ }^{3}$

\begin{abstract}
RESUMO
A descrição da nova espécie de pterossauro Caiuajara dobruskii abriu caminho para o desenvolvimento de uma ampla gama de estudos paleontológicos, entre eles a análise tafonômica. Tal análise representa um estudo dos processos que ocorrem desde a morte do organismo até a incorporação final dos seus restos orgânicos nas rochas. Buscando interpretar características tafonômicas relacionadas ao transporte hidráulico, foi utilizado peças do acervo do Museu da Terra e da Vida - UnC numeradas como CP. V 1001a, CP.V 1001b, CP.V 1023 e CP.V 1024.Os ossos encontrados nessas peças foram identificados e nomeados, na sequência utilizando as informações contidas no banco de dados do Cenpáleo, foi possível posicionar as peças espacialmente. Permitindo que a angulação dos ossos em relação ao norte fosse determinada. Os valores obtidos foram organizados em diagramas de roseta para indicar o direcionamento e sentido dos restos esqueletais. Os diagramas de roseta mostraram direcionamentos preferenciais entre os quadrantes SE e NW para as peças CP. V 1001a e CP.V 1001b, e direcionamento preferencial NE e SW para a peça CP.V1024. Diferença que pode ser justificada pelos diferentes níveis estratigráficos em que as peças foram coletadas. De maneira geral os dados podem ser correlacionados a um fluxo hidráulico Leste - Oeste para as peças CP. V 1001a e CP.V 1001b e Nordeste para a peça CP. V 1024.
\end{abstract}

Palavras-Chave: Tafonomia. Pterossauros. Cainajara dobruskii.

\footnotetext{
${ }^{1}$ Artigo elaborado como exigência da bolsa do Fundo de Apoio a Pesquisa - FAP.

${ }^{2}$ Discente do curso de Ciências Biológicas - Bacharelado da Universidade do Contestado. Campus Mafra. Santa Catarina. Brasil. E-mail: morganadw@outlook.com

${ }^{3}$ Professor orientador. Graduação em Geologia PUC, mestrado em Geologia PUC, Doutorado em Geologia estratigráfica. Centro Paleontológico da Universidade do Contestado - CENPALEO. Santa Catarina. Brasil. E-mail: luizw@unc.br
} 


\title{
ANALYSIS OF THE TRANSPORTABILITY OF SKELETAL REMAINS OF THE BONE BED OF PTEROSSAUROS OF CRUZEIRO DO OESTE, CAIUÁ GROUP, CRETACEOUS OF THE SEDIMENTARY PARANÁ BASIN
}

\begin{abstract}
The description of the new pterosaur species Caiuajara dobruskii opened the way for the development of a wide range of paleontological studies, including taphonomic analyzes. This analysis represents a study of the processes that occur from the death of the organism to the final incorporation of its organic remains in the rocks. In order to interpret taphonomic characteristics related to hydraulic transport, pieces of the Caiuá Sandstone housed at the collection of the Museum of Earth and Life - UnC numbered as CP.V 1001a, CP.V 1001b, CP.V 1023 and CP.V 1024. The bones found in these pieces were identified and named. In the sequence using the information contained in the Cenpaleo database, it was possible to position the pieces spatially. It allowed the angulation of the bones in relation to the north to be determined. The values obtained were organized in rosette diagrams to indicate the targeting and direction of the skeletal remains. The rosette diagrams showed preferred directions between the SE and NW quadrants for the pieces CP.V 1001a and CP.V 1001b, and preferential targeting NE and SW for the piece CP.V1024. Difference that can be justified by the different stratigraphic levels in which the pieces were collected. In general, the data can be correlated to an East - West hydraulic flow for pieces CP.V 1001a and CP.V 1001b and Northeast for the piece CP. V 1024.
\end{abstract}

Keywords: Taphonomy. Pterosaurs. Caiuajara dobruskii.

\section{INTRODUÇÃO}

Os pterossauros foram répteis contemporâneos aos dinossauros, representando os primeiros organismos adaptados ao voo ativo. Os primeiros registros de pterossauros datam do Triássico Superior com sua maior diversificação ocorrendo durante o Jurássico até sua extinção no final do Cretáceo. Durante esse longo período de tempo houve o surgimento de uma ampla gama de formas. Os mais basais como o Eudimorphodon, de pequeno porte, não ultrapassavam o tamanho de uma gaivota, até formas gigantescas, como o Quetzalcoatlus, com mais de dez metros de envergadura (BENTON, 2008).

A forma básica dos pterossauros pode ser resumida em algumas características principais, sendo elas: corpo curto com pescoço longo, quatro dígitos na mão, sendo um deles modificado para sustentar a membrana alar, presença de um osso no pulso chamado pteróide, crânio grande, ossos da pelve reduzidos e fusionados e mandíbulas pontudas (BENTON, 2008). 
Encontrar fósseis de pterossauro é um evento raro, principalmente devido a constituição dos ossos desses organismos que possuíam paredes muito finas (milímetros de largura). Essa propriedade tornava esses ossos muito frágeis e fáceis de serem diluídos, impedindo sua preservação fossílifera (KELLNER, 1994).

Sua ocorrência no registro fossilífero é geograficamente ampla, sendo encontrados fósseis de pterossauro em todos os continentes. O continente europeu é detentor da maioria das espécies descritas, seguido pela América do Norte e Ásia, África, América do Sul, Austrália e Antártica (BARRETT et al., 2008).

A descoberta da espécie de pterossauro Caiuajara dobruskii na região sul do Brasil, na cidade de Cruzeiro do Oeste, noroeste do estado do Paraná, em arenitos pertencente à Formação Goio-Erê, Grupo Caiuá, representou um evento único no estudo de pterossauros, por se tratar da primeira aparição desses organismos fora da região nordeste do país e também por estar longe de regiões costeiras, representando uma raríssima aparição no interior de continente (MANZIG et al., 2014).

Análises tafonômicas estão dentre os vários estudos que podem ser realizados utilizando o material encontrado na cidade de Cruzeiro do Oeste. A Tafonomia representa uma área recente da paleontologia, que se preocupa em descrever e interpretar os processos pelos quais o resto orgânico passou até tornarse um fóssil propriamente dito (CARVALHO, 2010).

A análise tafonômica engloba uma grande variedade de processos a serem estudados, desde a morte e necrólise até a desarticulação, transporte, soterramento e diagênese do fóssil (HOLZ; SIMÕES, 2002).

Ao que se refere especificamente aos padrões de transportabilidade de restos esqueletais de vertebrados em regiões continentais, o agente transportador (água), realiza processos de seleção dos restos ósseos, permitindo que sejam realizadas interpretações referentes aos regimes hidráulicos do local em épocas pretéritas (paleocorrentes), para tal, utiliza-se principalmente estudos realizados por Voorhies (1969) (CARVALHO, 2010; HOLZ; SIMÕES, 2002).

Voorhies definiu três grupos de ossos conforme sua transportabilidade. Grupo I, formado por ossos facilmente transportados, como tarsais, carpais e falanges. Grupo II, formados por ossos que se movem gradualmente por meio de processos de saltação e rolamento, como fêmures, úmeros, tíbias e costelas e Grupo III, formado por ossos pesados que sofrem pouco ou nem sequer sofrem transporte, como por exemplo, crânios e mandíbulas (HOLZ; SIMÕES, 2002).

Baseando-se nesses princípios da transportabilidade hidráulica, o presente estudo buscou identificar e interpretar padrões de transportabilidade hidráulica observados na tafocenose parautóctone de Cruzeiro do Oeste- PR, utilizando para isso peças tombadas no acervo do Museu da Terra e da Vida/UnC. 


\section{CARACTERÍSTICAS GEOLÓGICAS}

O Grupo Caiuá é constituído pela Formação Paraná, Formação Gôio Erê e Formação Santo Anastácio. Os achados fósseis utilizados no presente trabalho foram feitos na Formação Gôio Erê. Esta formação está presente apenas no estado do Paraná, no extremo sudeste da Bacia Sedimentar do Paraná/Bacia Bauru (FERNANDES; COIMBRA, 2000).

É constituída por arenitos quartzosos, rnarrom-avermelhados a cinzaarroxeados, finos a muito finos (ocasionalmente médios), subarcoseanos, mineralogicamente maturos e texturalmente submaturos. Possui como contexto deposicional depósitos de áreas periféricas de sand sea, com dunas eólicas de porte moderado, com cristas sinuosas e interdunas úmidas ou aquosas (FERNANDES; COIMBRA, 2000).

Os fósseis de pterossauro foram encontrados no leito de um trecho de uma estrada rural á $5 \mathrm{~km}$ ao Norte do centro da cidade. Envoltos num total de três pacotes de arenito, onde o pacote inferior possuía poucas ocorrências fósseis, desarticuladas e espaçadas, no nível intermediário havia poucos fósseis, mas apresentando certo grau de articulação e por fim o nível superior onde se encontrava grande quantidade de ossos muito desarticulados, alguns preenchidos por sedimentos ou cristalizados por calcita (MANZIG; WEINSCHÜTZ, 2012, MANZIG et al., 2014).

\section{MATERIAIS E MÉTODOS}

A fim de analisar o direcionamento do agente transportador (água) e a diferença de transportabilidade entre ossos distintos, foram selecionadas quatro peças tombadas junto ao Museu da Terra e da Vida/Cenpaleo, anteriormente utilizadas na descrição da espécie de pterossauro Caiuajara dobruskii. As peças utilizadas foram CP.V 1001a, CP.V 1001b, CP.V 1024 e CP.V 1023.

As peças empregadas no estudo foram retiradas de blocos coletados na cidade de Cruzeiro do Oeste, onde estes foram recolhidos com informações quanto ao topo e orientados em relação ao Norte, sem essas informações do momento da coleta as análises de paleocorrentes e direcionamentos preferenciais não seriam possíveis.

Os ossos presentes nas peças foram identificados e nomeados e seus vetores tabulados e organizados em diagramas de roseta para indicar as orientações predominantes. Para a confecção dos diagramas foi utilizado o programa de desenho CoreIDRAW X5. 


\section{RESULTADOS E DISCUSSÕES}

No total foram tomadas atitudes de 8 ossos do bloco CP.V 1001a, 8 ossos do bloco CP.V 1001b, 8 ossos do bloco CP.V 1024. Os dados referentes ao posicionamento espacial do bloco CP.V 1023 presentes no banco de dados do Cenpaleo eram insuficientes para a determinação do seu posicionamento espacial em relação ao Norte, por isso, essa peça não foi utilizada.

Os diagramas de roseta das peças analisadas indicaram um padrão de transportabilidade para as peças CP.V 10001a e CP.V 1001b e outro para a peça CP.V 1024. Enquanto que na primeira e segunda peça observou-se um direcionamento preferencial entre os quadrantes SE e NW, a última apresentou um direcionamento preferencial entre NE e SW.

A seguir encontram-se as fotos das peças utilizadas, com seus ossos identificados e seus respectivos diagramas de roseta indicando 0 sentido preferencial dos ossos.

Figura 1 - Peça e diagrama de roseta referente a peça CP.V 1001a
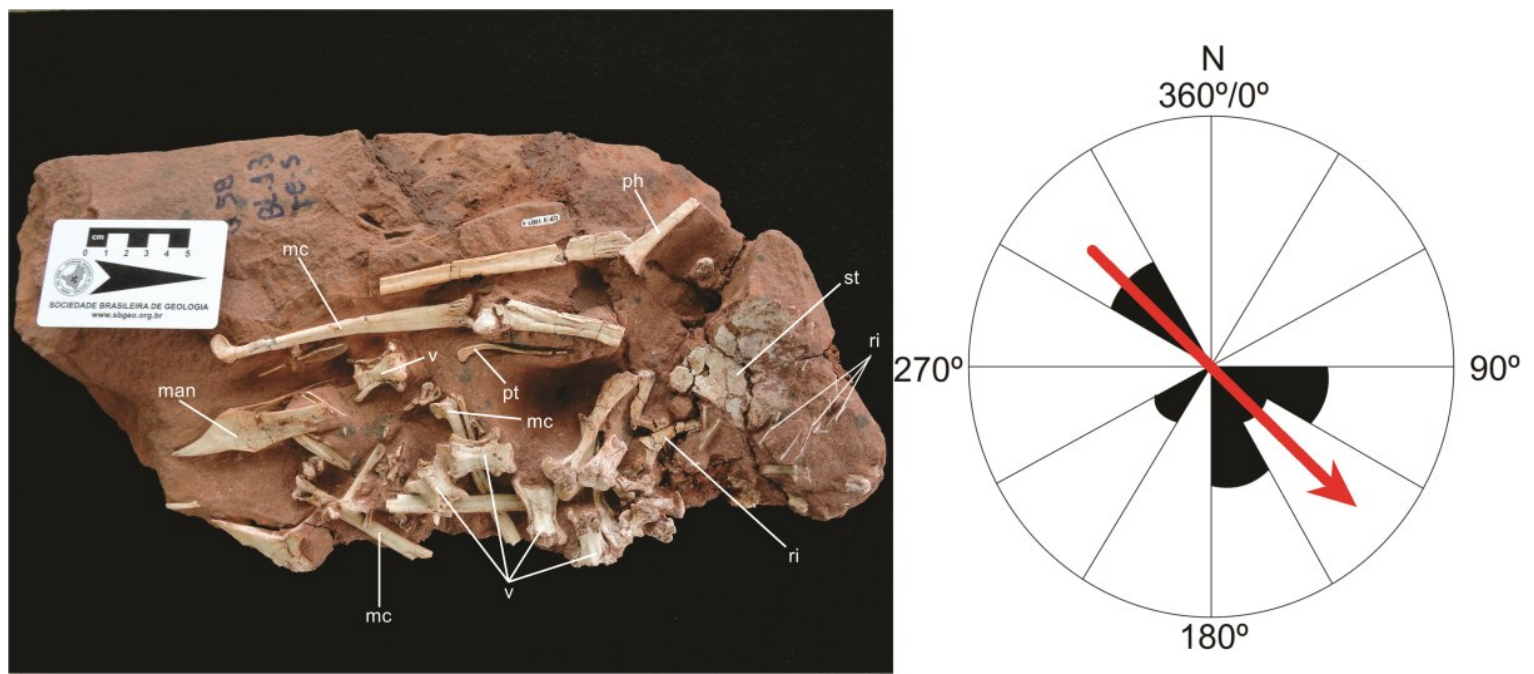

Fonte: Wantowsky, (2017). 
Figura 2 - Peça e diagrama de roseta referente a peça CP.V 1001b
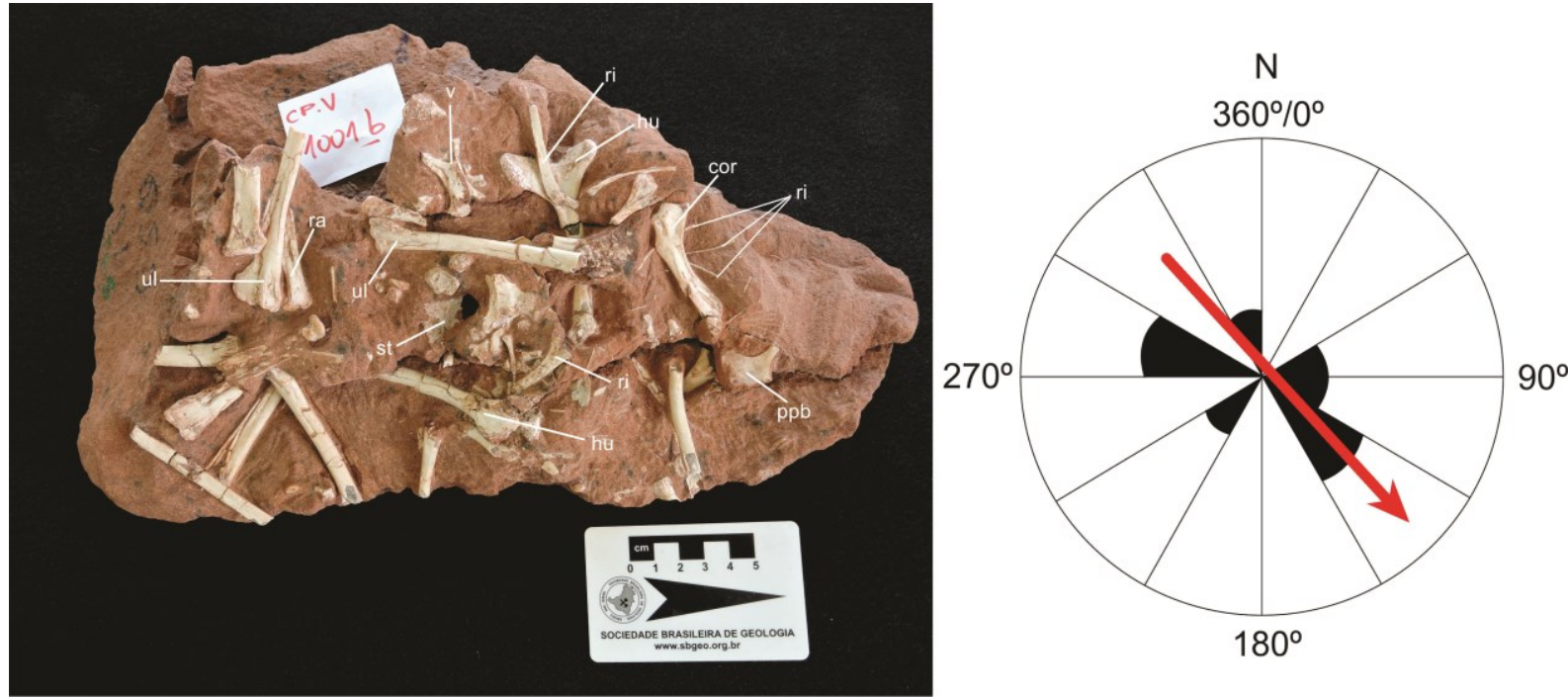

Fonte: Wantowsky, (2017).

Figura 3 - Peça e diagrama de roseta referente a peça CP.V 1024
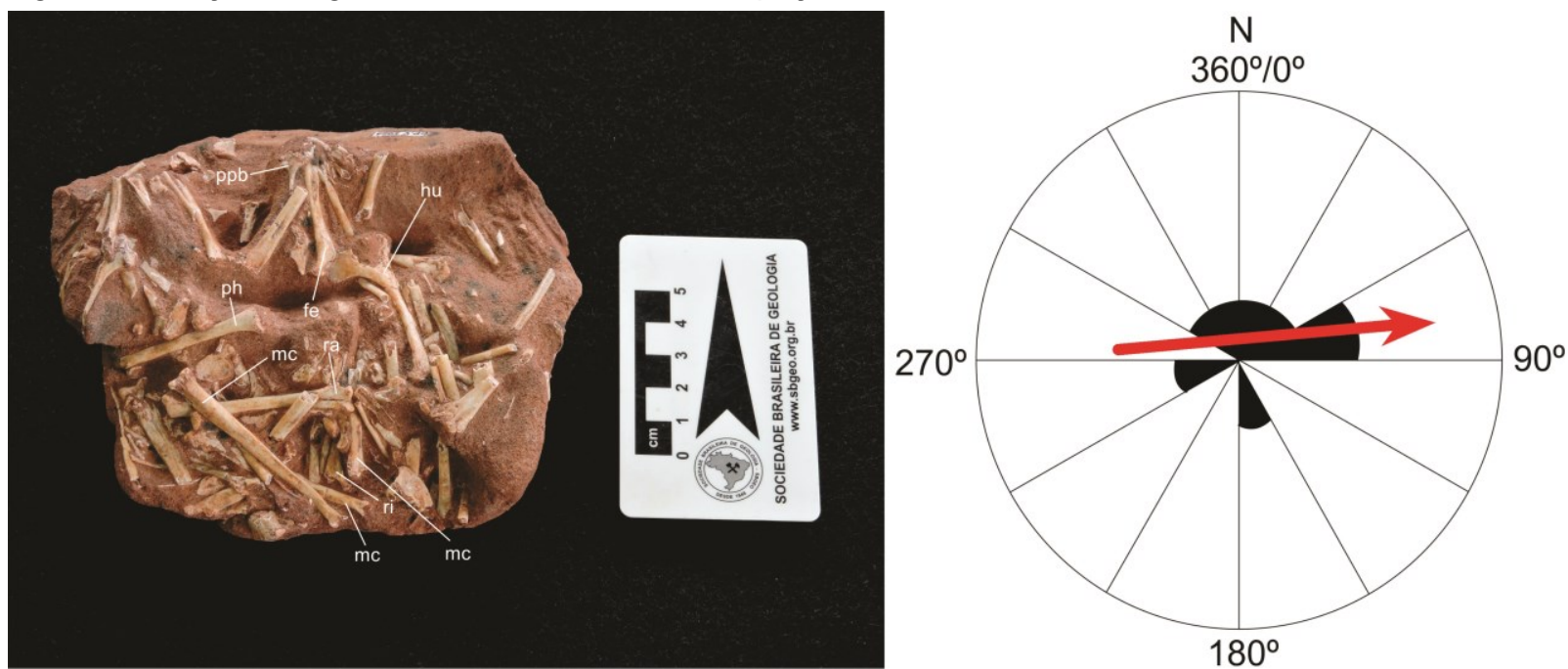

Fonte: Wantowsky, (2017).

Os blocos CP.V 1001a e CP.V 1001b pertencem ao mesmo nível estratigráfico, o que explica ambas possuírem um mesmo direcionamento, já a peça CP.V 1024 pertence a um nível estratigraficamente superior, que estava sujeito a condições diferentes de corrente, por isso um direcionamento preferencial distinto.

Os ossos utilizados nesse estudo pertencem à espécie de pterossauro Caiuajara dobruskii, sendo os pterossauros dotados de um esqueleto com ossos com paredes de pouco espessura, o que lhe confere um peso muito reduzido, próprio para os regimes de vôo, e que resultou em algumas mudanças nos grupos de Voorhies.

Crânios e mandíbulas encontram-se no Grupo III, nesse grupo estão incluídos os elementos esqueletais pesados, que formam os chamados "depósitos residuais", 
devido a sua dificuldade em serem transportados (CARVALHO, 2010). Porém, ao se observar os crânios e mandíbulas de pterossauros percebe-se que os mesmos são leves e possuidores de formato alongado e hidrodinâmico, o que facilitaria seu transporte, sendo encontrados junto a ossos leves, como falanges e metacarpos.

\section{CONSIDERAÇÕES FINAIS}

Os restos esqueletais do bone bed de Cruzeiro do Oeste, PR, apresentam origem a partir de fluxos esporádicos de água em areias eólicas ao redor de possíveis oásis. Pela análise da disposição final dos ossos é possível reconhecer que a direção deste fluxo era preferencialmente Leste-Oeste e na peça CP.V 1024 é possível inferir o sentido do fluxo para Nordeste, diferença decorrente principalmente devido ao posicionamento em diferentes níveis.

\section{REFERÊNCIAS}

BARRETT, P.M. et al. Pterosaur distribution in time and space: an atlas. Zitteliana, v. 28, p.61-107, 2008.

BENTON, Michael J. Paleontologia dos Vertebrados. 3. ed. São Paulo: Atheneu Editora, 2008.

CARVALHO, Ismar de Souza. Paleontologia: conceitos e métodos. 3.ed. Rio de Janeiro: Interciência, 2010. v. 1

FERNANDES, Luiz Alberto; COIMBRA, Armando Márcio. Revisão Estratigráfica da Parte Oriental da Bacia Bauru (Neocretáceo). Revista Brasileira de Geociências, v. 30, n. 4, p.717-728, dez. 2000.

HOLZ, Michael; SIMÕES, Marcello G. Elementos Fundamentais de Tafonomia. Porto Alegre: Ed. Universidade/ufrgs, 2002.

KELLNER A.W.A. Remarks on pterosaur taphonomy and paleoecology. Acta Geologica Leopoldensia v. 39, p. 175-189, 1994.

MANZIG, Paulo C. et al. Discovery of a rare pterosaur bone bed in a Cretaceous desert with insights on ontogeny and behavior of flying reptiles. Plos One, v. 9, n. 8, ago. 2014.

MANZIG, Paulo; WEINSCHÜTZ, Luiz Carlos. Museus e Fósseis da Região Sul do Brasil. Marechal Cândido Rondon: Editora Germânica, 2012.

Artigo recebido em: 12/12/2017

Artigo aprovado em: 04/11/2018

Artigo publicado em: 06/12/2018 